* Doutor em Direito em 2012 pela Universidade de Brasília (UNB) Mestre em Direito em 2006 pela Universidade pela Universidade de Brasília (UNB)

Graduado em Direito em 2004 pelo Centro Universitário Toledo (UNITOLEDO)

E-mail: $\quad$ danielbarile@,hotmail. com

** Mestrando em Direito pela Universidade de Marília (UNIMAR)

Especialista em Direito do Estado em 2011 pela Universidade Estadual de Londrina (UEL)

Graduado em Direito em 2005

pelo Centro Universitário de

Votuporanga (UNIFEV)

E-mail: c_hmj@hotmail.com

\section{O Compliance E Seus Reflexos No Direito BRASILEIRO}

Compliance And Its Reflections In Brazilian LaW

\section{Daniel Barile da Silveira* Carlos Henrique Miranda Jorge*}

Como citar: SILVEIRA, Daniel Barile; JORGE, Carlos Henrique Miranda. O compliance e seus reflexos no direito brasileiro. Scientia Iuris, Londrina, v. 23, n. 1, p. 125-143, mar. 2019. DOI: 10.5433/2178-8189.2019v23n1p125. ISSN: 2178-8189.

Resumo: O presente trabalho visa analisar uma nova ferramenta no combate à corrupção no país, mal que assola e atinge todos os setores da nossa sociedade, com consequências desastrosas em diversos setores como saúde, educação, segurança pública, trazendo uma estagnação política e econômica, além do descrédito da população nas instituições. Dessa forma, iniciase pelo histórico da ferramenta compliance trazida pela Lei $12.846 / 13$, passando por seus reflexos em alguns ramos do Direito. Posteriormente, passa-se a análise da lei anticorrupção, trazendo os pontos positivos e críticas que advieram com sua promulgação, trazendo uma sucinta analogia com demais leis do ordenamento jurídico, analisando demais inovações junto a ela com o intuito de evitar atos ilícitos na pessoa jurídica, demonstrando a sustentabilidade que tais medidas poderiam trazer ao país caso fossem colocadas em prática, às consequências do seu descumprimento e as respectivas sanções civis e administrativas. Em conclusão, verificamos que o ordenamento jurídico brasileiro já possui diversas leis no combate as condutas ilícitas e práticas de corrupção, trazendo mais eficiência se as instituições responsáveis pelas investigações e o Poder Judiciário fossem melhores estruturados e aparelhados.

Palavras-chave: Compliance. Corrupção. Lei 12.846/13.

Abstract: This paper aims at analyzing a new tool in the fight against corruption in the country, which is bad for all sectors of our society, with disastrous consequences in several sectors such as health, education, public security, bringing political and economic stagnation, besides discredit the population in the institutions. In this way, it begins with the history of the compliance tool brought by Law 12.846 / 13, passing through its reflexes in some branches of Law. Subsequently, the analysis of the anti-corruption law is passed, bringing the positive and 
critical points that came with its promulgation, bringing a succinct analogy with other laws of the legal system, analyzing other innovations with it with the intention of avoiding illegal acts in the legal entity, demonstrating the sustainability that such measures could bring to the country if they were put into practice, the consequences of their non-compliance and the respective civil and administrative sanctions. In conclusion, we verified that the Brazilian legal system already has several laws in the fight against illegal practices and practices of corruption, bringing more efficiency if the institutions responsible for investigations and the Judiciary Power were better structured and equipped.

Keywords: Compliance. Corruption. Law 12.846 / 13. 


\section{INTRODUÇÃO}

A corrupção vem trazendo prejuízos enormes ao Brasil em todos os setores, chegando, fazendo com que Estados permaneçam em extrema dificuldade financeira, com reflexos imediatos nos mais diversos setores das políticas públicas estatais. A eficiência do Estado, por certo, está diretamente associada ao trato para com a corrupção, no contexto de que as políticas de integridade instituídas buscam inevitavelmente que os objetivos estatais se consolidem, enquanto máquina pública executora de atividades, mas que também suas práticas se estruturem por meios lícitos e éticos.

Em meio a uma das maiores crises políticas vividas pelo país, foi promulgada no ano de 2013 a Lei 12.846/13, advinda do Projeto de Lei $n^{\circ}$. 6.826/2010 proposto pela Controladoria Geral da União, conhecida popularmente como "lei anticorrupção", visando trazer novos instrumentos que facilitem o combate aos atos ilícitos que trazem graves danos ao erário. Tratou-se da busca normativa de instituição de uma nova mentalidade em relação a conceitos éticos em meio a negócios públicos, além de trazer a responsabilização de pessoas jurídicas que vierem a causar lesão a Administração Pública.

Entretanto, por mais importante e disruptiva que seja a lei, alguns questionamentos minam sua aplicabilidade prática, fazendo exsurgir do debate público alguns pontos de crítica à lei. Em um primeiro momento, há de se avaliar se a presente lei permite, de fato, à estruturação de uma política estatal de combate efetivo à corrupção, muito mais do que um instrumento simbólico de reverberação de tratados internacionais e de construção de imagem ética do Estado Nacional perante organismos internacionais. Ainda, outra questão importante é de se saber se a Lei 12.846/13 não trouxe dispositivos inconstitucionais, no contexto de se buscar o fim preconizado pelos seus autores a um custo constitucional irrefletido.

De tal forma, o objetivo geral deste artigo é descrever os institutos mais importantes trazidos pela Lei 12.846/13 para o combate aos atos de corrupção praticados por agentes públicos e pessoas jurídicas que tenham relação com a Administração Pública, propiciando a análise crítica e científica do processo.

A partir de um método dedutivo-indutivo, coletado de material bibliográfico pertinente, tal estudo buscará investigar os pontos mais importantes da lei, com uma proposta mais explícita de se buscar superar tais questionamentos no intuito de garantir a eficácia jurídica desejada de tal instrumento legislativo.

Do ponto de vista da estruturação do texto, o presente artigo se divide em duas partes: primeiramente, intenta investigar as origens que propiciaram o desenvolvimento dos institutos trazidos pela lei. Já em um segundo turno, avalia os elementos mais importantes que consolidam este documento jurídico como um importante veículo de combate aos males que atingem a administração pública nos tempos atuais.

\section{BREVE HISTÓRICO SOBRE O SURGIMENTO DO COMPLIANCE}


Com o avanço cada vez maior da globalização, aumentou-se cada vez mais os riscos dos negócios empresariais, sendo necessária a busca de meios para evitar atos de corrupção e outros que possam trazer prejuízos à sociedade.

Assim, torna-se necessário a empresa ter novo papel diante da sociedade, de maneira que o resultado empresarial isoladamente não representa tão somente o resultado finalístico de uma empresa. $\mathrm{O}$ envolvimento de suas atividades com preceitos éticos passou a ser uma nova demanda socialmente exigida, consolidando uma política de governança corporativa como padrão de atuação no mercado.

Dessa forma, surge a necessidade de se implantarem métodos para que as empresas possam agir de maneira cada vez mais transparente e ética nos negócios, assim como para diminuir os casos de corrupção existentes, refletindo de forma positiva na sociedade em sua sustentabilidade. Surge, assim, a figura do "compliance" como forma de garantir uma cooperação mútua no ambiente empresarial, definindo a forma de atuação de seus funcionários, da mesma maneira em como a empresa agirá no mercado que opera. Trata-se de um modelo aplicável a todos os tipos de organização.

Gabardo e Castella (2015, p. 134) assim define o compliance:

O compliance pode e deve ser utilizado, tanto como uma ferramenta de controle, proteção e prevenção de possíveis práticas criminosas nas empresas, como um valioso instrumento de transferência de responsabilidade, evitando ou amenizando a responsabilidade da pessoa jurídica quando do surgimento de alguma patologia corruptiva.

Quanto a origem do termo, os mesmos autores acima trazem dessa forma:

A ideia surgiu por intermédio da legislação norte-americana, com a criação da Prudential Securities, em 1950, e com a regulação da Securities and Exchange Commission (SEC), de 1960, onde se fez menção à necessidade de institucionalizar os programas de compliance, com a finalidade de criar procedimentos internos de controle e monitoramento das operações entre pessoas. Alguns anos depois, precisamente em nove de dezembro de 1977, registrou-se na Europa a Convenção Relativa à Obrigação de Diligência dos Bancos no Marco da Associação de Bancos Suíços, instituindo as bases de um sistema de autorregulação de conduta, vinculando as instituições, cujo descumprimento resultaria na aplicação de sanções como multas e outras penalidades. Ainda, merece destaque o Ato Patriótico dos Estados Unidos, de outubro de 2001, criado logo após os atentados terroristas de 11 de setembro. Em seu artigo 352, foi estabelecido que as entidades financeiras deverão desenvolver políticas e procedimentos de controle interno, com o intuito de proteger-se contra a lavagem de dinheiro (GABARDO; CASTELLA, 2015, p. 134).

A forma como o compliance se implementa no país advém de diversos documentos de órgão internacionais que possuem este ramo de atividade, como Comitê de Supervisão 
Bancária da Basiléia, o Acordo da Basiléia I - 1998, o Acordo da Basiléia II, o Fundo Monetário Internacional(FMI), Grupo de Ação Financeira Internacional - GAFI, entre outras referências mais setorizadas, presentes no continente europeu e nos Estados Unidos.

Compliance possui, entre os seus objetivos, organizar documentação e procedimentos, gerenciando de forma adequada os riscos e exaltando a transparência, de alcance amplo e não apenas cumprimento de regras formais ou informais. Está ligado ao conceito de "governança corporativa", ou seja, de sistemas de organização empresarial, tendo como um dos objetivos diminuir a responsabilidade objetiva da empresa, utilizado para contenção de riscos, com o comprometimento da empresa no cumprimento da legislação em vigor, a partir de procedimentos internos que visam uma maior transparência em seus atos e decisões.

Portanto, cada ramo da atividade estará exposto aos mais diversos riscos normativos e que se fundamentam de modo inerentes à atividade desenvolvida. Com isso, não há que se falar em um modelo considerado como o verdadeiro padrão de programa de cumprimento, que deverá ser construído e analisado a partir de cada caso concreto (ASSIS, 2006, p. 61).

No Brasil, em consonância a este movimento global de organização das empresas para o combate a práticas ilícitas, a Lei 12.846/13 estabelece que o fim por ela visado é de buscar a responsabilização objetiva administrativa e civil de pessoas jurídicas pela prática de atos contra a administração pública, nacional ou estrangeira (art. $1^{\circ}$ ). Nestes moldes, a figura do compliance vem estabelecida em seu art. $7^{\circ}$, inciso VII, estabelecendo a necessidade da construção de mecanismos e procedimentos internos de integridade, auditoria e incentivo à denúncia de irregularidades e a aplicação efetiva de códigos de ética e de conduta no âmbito da pessoa jurídica. Assim, prever, prevenir, controlar e punir atos corruptivos é sua intenção mais imediata (BRASIL, 2013).

Inegavelmente, o contexto de aplicação do compliance se espiraria por diversas áreas do Direito, impactando o cenário da empresa nestes mais diversos contextos. Importante é se buscar um olhar mais atento a estes campos de atuação.

\subsection{O compliance no direito do trabalho}

Com o alcance e avanço com que o compliance trouxe a legislação brasileira através da lei anticorrupção, torna-se imprescindível uma análise deste junto a alguns ramos do Direito, no intuito de verificar sua abrangência e relevância. Assim, claramente salutar o estudo da lei anticorrupção junto ao Direito do Trabalho.

Assim, as formas de contratações nas empresas podem reduzir consideravelmente a corrupção, assim como diversas fraudes em instâncias trabalhistas podem ser reduzidas com implantações de métodos eficientes de treinamento e melhoramento na escolha de empregados, mesmo que evidentemente seja impossível detectar em um treinamento todas atitudes que um futuro empregado possa vir a cometer. 
Oliveira (2015, p. 9) entende que:

[...] é nesse estágio que a empresa inicia o seu dever legal de cumprir a Lei, pois um processo de contratação bem conduzido e uma política de treinamento bem elaborada podem antever problemas que só depois do dano seriam constatados. Uma política sólida e robusta que inicie no momento das contratações e se estenda pelo decorrer do vínculo - seja empregatício, seja contratual - é de extrema importância para evitar desvios dentro da companhia.

Tais atitudes também fariam com que o $\S 2^{\circ}$ do art.20 da Lei $12.846 / 13$ não fossem aplicados as empresas que mantiveram e que sabiam de algum ato que geraria dano no futuro, pois mesmo que tais atos fossem originários de uma empresa terceira, também poderá trazer penalidades também a empresa que tenha sido conivente com as atitudes ilegais.

Outra questão que também passa por comportamentos éticos dentro de uma empresa e pode ser diminuído através de cursos, treinamentos e demais medidas, refere-se às demandas judiciais entre reclamante e reclamado que possuem por única finalidade a obtenção de homologação judicial. Não bastasse, diversas ações dessa seara com pretensões fraudulentas do reclamante junto ao reclamado para que haja proteção de seu patrimônio face a um empregado de confiança que futuramente irá restituir o valor pago de forma integral, evitando que seu patrimônio se dilapide junto aos credores, movimentando todo o aparato judicial para a solução da lide, mas que na realidade está sendo utilizada apenas como forma de formalizar uma fraude, o que traz prejuízos ao patrimônio público.

Entretanto, embora o compliance possa evitar todo o acima mencionado, surgem dúvidas em relação à forma com que o empregado possa denunciar eventuais práticas relacionadas a ilícitos que o empregador realize ou determine que este realize, permanecendo sempre em situação fragilizada diante desse tipo de situação. Neste contexto, um canal de denúncias deverá ser criado pela própria empresa, gerando o questionamento se ele é totalmente confiável, bem como se seu uso será explorado pelo empregado. A efetividade deste modelo chama a atenção e merece, certamente, uma avaliação mais individualizada de seu funcionamento.

\subsubsection{Compliante no direito ambiental}

Um dos assuntos que estão em maior evidência atualmente relaciona-se ao meio ambiente. Procura-se cada vez mais manter um equilíbrio entre desenvolvimento sustentável e meio ambiente equilibrado. Certo é que muitas empresas no intuito de obter cada vez mais lucro vem desenfreadamente poluindo e desrespeitando todas as normas atinentes à esfera ambiental, causando desequilíbrio e danos ao meio ambiente, e, consequentemente, à sociedade.

Mesma com inúmeras leis penais ambientais, cíveis e administrativas elaboradas no intuito de prevenir danos ambientais, inúmeros são os casos que empresas poluem rios, córregos, desmatam áreas proibidas, causam incêndios propositalmente, entre outras condutas. Com a 
elaboração de códigos de conduta, cursos de aperfeiçoamento e uma maior conscientização por parte da empresa busca-se sanar esta prática impiedosa para com o meio ambiente.

Entretanto, a prática do compliance não passa apenas por questões de treinamentos e métodos preventivos, mas também por uma maior conscientização social sobre o meio ambiente e seu legado a gerações futuras. Algumas práticas já vêm sendo adotadas por empresas, como reciclagens e reaproveitamento de alguns materiais, entretanto, não vem sendo suficiente para conter a devastação que está ocorrendo, ocasionando a elevação de temperaturas e alterações de fenômenos naturais.

A pessoa jurídica deve buscar, por meio da implantação de um programa de compliance, a prevenção de riscos por meio da adoção de um programa contínuo que vise a proteção da empresa e seus membros da responsabilização penal ou a redução de responsabilidades através da possível detecção de atos ilegais antes de seu cometimento.

De outro modo, mesmo que muitas empresas apresentem resistência no cumprimento da legislação ambiental por acreditarem que a adoção de medidas preventivas constitui algo custoso que não traz benefícios, a realidade demonstra que tal postura condenará a empresa na parte que lhe é mais cara, ou seja, o consumidor.

Todavia, a grande maioria das empresas tem enxergado oportunidades onde outras visualizam despesas. Porém, críticas surgem em relação aos custos de implementação desses programas, sem que haja uma política de incentivos fiscais, pois muitos são revertidos nos valores dos produtos que a empresa disponibiliza no mercado, trazendo um custo maior ao consumidor final.

\subsubsection{Compliance criminal}

Como demonstrado anteriormente, o compliance está intimamente ligado a diversos ramos do Direito através de formas preventivas e em questões trabalhistas e ambientais e que trazem consequências não apenas na ordem jurídica, mas também em toda sociedade. Não diferente ocorre no Direito Penal.

Diversamente do trazido pelo Direito Penal, em que o crime é estudado após a ocorrências do fatos, o compliance criminal visa sua prevenção através de controles internos nos procedimentos e atitudes a serem tomadas que possam evitar responsabilização penal a serem enfrentados pela empresa, tendo a pretensão da combater a atividade ilícita antes que ela seja praticada.

Com a entrada em vigor da Lei $n^{\circ} 12.683 / 12$ referente a Lavagem de Dinheiro, também conhecida como "Lei da Empresa Limpa", as empresas iniciaram um processo maior para fiscalização interna, aumentando os setores a adotarem programas de compliance para que se possa evitar tal prática, trazendo medidas que outros países já estavam adotando, utilizando-o como forma de diminuir eventual sanção penal que possa advir, assim como a responsabilidade objetiva da empresa nos casos de corrupção que as envolvam.

Assim, surgiu a obrigação de as instituições financeiras e as empresas do mercado de 
seguros em geral de comunicar quaisquer operações que sejam suspeitas e que possam configurar o crime de lavagem de dinheiro, atentando-se a todas as formas de combater e prevenir o sistema financeiro de atos ilícitos.

Contudo, tais práticas também são recebidas de forma críticas, pois, no dizeres de Saavedra (2016, p. 248):

[...] como se pode ver, o desenvolvimento do Compliance parece implicar em um paradoxo. O objetivo de Compliance é claro: a partir de uma série de controles internos se pretende prevenir a responsabilização penal. A sua concretização, porém, ao invés de diminuir as chances de responsabilização penal, cria as condições para que, dentro da empresa ou instituição financeira, identifiquese uma cadeia de responsabilização penal, pois a forma como os Compliance Officers têm sido constituídos acabam por colocá-los na posição de garante. Com isso, as chances de responsabilização penal aumentam ao invés de diminuir, ou seja, a criação de Compliance Officers, que deveria zelar pela diminuição de riscos compliance acaba, paradoxalmente, por aumentá-los, principalmente, porque os Compliance Officers, por sua vez, segundo doutrina majoritária, devem ser supervisionados diretamente pelo Conselho de Administração (ou órgão similar de gerência da empresa) fato que, obviamente, coloca em risco de persecução penal toda a administração da empresa.

De certa forma o Estado acaba determinando que empresas assumam o ônus de verificação de atividades ilícitas em suas atividades, garantindo assim que caso ocorra alguma prática criminal os bens resultantes dela sejam recuperados com maior facilidade.

O art.10 da Lei 9.613/98 traz os deveres que as pessoas físicas e jurídicas devem ter nos programas instituídos, sendo eles : I - identificarão seus clientes e manterão cadastro atualizado, nos termos de instruções emanadas das autoridades competentes; II - manterão registro de toda transação em moeda nacional ou estrangeira, títulos e valores mobiliários, títulos de crédito, metais, ou qualquer ativo passível de ser convertido em dinheiro, que ultrapassar limite fixado pela autoridade competente e nos termos de instruções por esta expedidas; III - deverão adotar políticas, procedimentos e controles internos, compatíveis com seu porte e volume de operações, que lhes permitam atender ao disposto neste artigo e no art. 11, na forma disciplinada pelos órgãos competentes; IV - deverão cadastrar-se e manter seu cadastro atualizado no órgão regulador ou fiscalizador e, na falta deste, no Conselho de Controle de Atividades Financeiras (COAF), na forma e condições por eles estabelecidas; $\mathrm{V}$ - deverão atender às requisições formuladas pelo Coaf na periodicidade, forma e condições por ele estabelecidas, cabendo-lhe preservar, nos termos da lei, o sigilo das informações prestadas (BRASIL, 1998).

Na hipótese de o cliente constituir-se em pessoa jurídica, a identificação referida acima deverá abranger as pessoas físicas autorizadas a representá-la, bem como seus proprietários. Por sua vez, os cadastros e registros referidos deverão ser conservados durante o período mínimo de cinco anos a partir do encerramento da conta ou da conclusão da transação, prazo este que poderá 
ser ampliado pela autoridade competente.

Surge, assim, neste contexto, um debate sobre quais seriam as consequências em relação ao descumprimento do compliance pela empresa: se seria passível de punição na esfera criminal ou apenas na órbita administrativa. Há posições divergentes a respeito. Inicialmente, há uma corrente que entende que o descumprimento das normas estabelecidas implicaria na incidência dos art.16 e 22 da Lei 9.613/98 que trazem situações em que há operação sem a devida autorização e efetuar operação não autorizada, sendo ambas punidas com pena de reclusão (BRASIL, 1998).

Em contrapartida, outra corrente entende que a lei que define os crimes contra o Sistema Financeiro Nacional não tem relação com as práticas de compliance, sendo essa apenas contemplada pela Lei de Lavagem de Capitais, $n^{\circ}$ 9.613/98, implicando apenas em sanções administrativas.

\section{DA LEI ANTICORRUPÇÃO 12.846/13}

Conforme dito anteriormente, a lei anticorrupção veio atender compromissos internacionais e reinvindicações dos brasileiros diante de diversos escândalos de corrupção que ganharam notoriedade após uma das maiores operações da Policia Federal no combate a diversos crimes que envolveram políticos, empreiteiras, conhecida como operação "Lava-Jato", que levou milhões de brasileiros às ruas por uma país mais transparente, ético e pelo fim da corrupção no meio político.

Segundo Ribeiro e Diniz (2015, p. 93) um estudo realizado pela Federação das Indústrias do Estado do Paraná, com base em dados de 1990 a 2008, traz informações sobre os custos de transação decorrentes da corrupção no Brasil:

As perdas econômicas e sociais do Brasil com a corrupção foram estimadas considerando um nível de corrupção percebida no país igual à média de uma cesta de países selecionados. Se o Brasil possuísse um nível de percepção da corrupção igual à média desses países de 7,45, o produto per capita do país passaria de US\$ 7.954 a US\$ 9.184, ou seja, um aumento de $15,5 \%$ na média do período 1990 2008 (equivalente a $1,36 \%$ ao ano). Isto corresponde a um custo médio anual da corrupção estimado em R $\$ 41,5$ bilhões, correspondendo a 1,38\% do PIB (valores de 2008). Se o controle da corrupção fosse ainda mais rigoroso, estimase que todos os recursos liberados da corrupção para as atividades produtivas (isto é, o custo médio anual da corrupção) chegue a $\mathrm{R} \$ 69,1$ bilhões (valores de 2008), correspondentes a 2,3\% do PIB. No entanto, este valor corresponde a um referencial teórico, em que se considera um nível de percepção da corrupção tendendo a zero, condição que não foi observada por nenhum país até então.

Ainda, para que se pudesse garantir uma maior transparência em grandes competições esportivas que o país sediaria, aprovou-se no ano de 2013 o projeto de Lei $n^{\circ}$. 6.826/2010 proposto pela Controladoria Geral da União em 18 de fevereiro 2010. 
Surgiu então a Lei 12.846/13, com a finalidade de dispor sobre a responsabilização administrativa e civil de pessoas jurídicas pela prática de atos contra a administração pública, nacional ou estrangeira, adotando procedimento que não existiam em nenhuma legislação anterior.

O objetivo do anteprojeto de lei foi suprir a lacuna existente para responsabilização de pessoa jurídica pela prática de atos ilícitos contra a Administração Pública, especialmente por atos de corrupção e fraudes em licitação e contratos administrativos.

Essas lacunas se referem à ausência de meios específicos para atingir o patrimônio das pessoas jurídicas e obter efetivo ressarcimento dos prejuízos causados por atos que beneficiem a pessoa jurídica, assim como para atender aos compromissos internacionais assumidos pelo Brasil no combate a corrupção, como, por exemplo, o suborno transnacional, que seria a corrupção ativa de funcionário público estrangeiro e de organizações internacionais.

O projeto optou pela responsabilização administrativa e civil da pessoa jurídica, pois o Direito Penal não oferece mecanismos céleres para punir sociedades empresárias. Apesar de haver previsão de responsabilidade administrativa na lei de licitações para hipótese de atos lesivos praticados em licitação, possuía lacunas, sendo elas: a) Condutas mais graves são tratadas apenas na esfera criminal a qual não se aplica a pessoa jurídica que se beneficia da conduta; b) Não geram ressarcimento nem atinge de modo eficaz o patrimônio da pessoa jurídica.

Por sua vez, a lei de improbidade administrativa, lei n. 8.429/92, apenas responsabiliza civilmente o agente público e as pessoas que cometem os atos de improbidade, ainda que de forma conexa. Entretanto, ela não atinge a responsabilização penal da pessoa jurídica, novidade esta, trazida pela lei anticorrupção.

Destarte, surgiram críticas e dúvidas em relação a mais uma lei promulgada, em especial pela sua real efetividade e necessidade, se realmente teria o condão de tentar punir atos de corrupção ou se foi elaborada apenas para atender e diminuir o clamor público em determinado momento que o país estava vivendo o ápice de escândalos de corrupção. O ataque se deu porque há diversos diplomas legais com o mesmo objetivo, estabelecendo, inclusive, normas de conduta de funcionários, em especial na Administração Pública, como por exemplo, a Lei do Funcionalismo Público e contra atos ilegais como Lei da Ação Popular, Lei de Improbidade Administrativa, Lei da Ficha Limpa, Lei de Responsabilidade Fiscal, Crimes de Responsabilidade, entre outras que compõe, o que ocasionaria a sensação de excesso de lei, mesmo com algumas inovações que surgiram através dela.

Ainda, especificamente em relação a Administração Pública uma das críticas que surge é que o gestor público, no intuito de demonstrar sua probidade, transparência acaba executando atividades cada vez mais formais, burocráticas, o que muitas vezes contribui para a ineficiência no setor. Entende-se, ainda, que seria uma farsa formalizar a relação pública-privada com o discurso de compliance, pois não há boa prática que impede atividade desonesta e também porque há princípios constitucionais estabelecidos no art.37 da Constituição Federal que já norteiam todo o setor público, os quais independem de padrões, procedimentos ou rotinas de compliance (BRASIL, 1988). 
Por fim, outra crítica feita é de que a lei em estudo teria caráter elitista, na medida em que confere benefícios apenas em crimes do "colarinho branco", ou seja, uma legislação elaborada especificamente para quem possui maior poder aquisitivo, diversamente de diversas infrações penais comuns, as quais não fornecessem as mesmas benesses.

Como medidas de inovação do ordenamento jurídico no combate a corrupção o legislador trouxe quatro alternativas que não haviam sido trazidas anteriormente nas demais leis: i. a responsabilização objetiva da pessoa jurídica; ii. o programa de compliance, estabelecido no art. $7^{\circ}$, inciso VIII; iii. o acordo de leniência, estabelecido no art.16; e iv. o Cadastro Nacional de Empresas Punidas (BRASIL, 2013).

Todos estes pontos serão abordados de forma individualizada.

\subsubsection{Responsabilidade objetiva}

Trazida em seu art. $1^{\circ}$, a responsabilidade jurídica é objetiva para as pessoas jurídicas que causam lesividade e danos contra a Administração Pública. Desde que demonstrado o nexo de causalidade, o fato e o resultado que tal conduta tenha ocasionado, ocorrerá a responsabilização da empresa, independentemente de culpa.

No entanto, há entendimento diverso que vislumbram os atos de corrupção serem praticados apenas por pessoas físicas, necessitando do dolo e que as pessoas jurídicas não poderiam responder por tais atos.

Assim menciona Justen Filho (2013, p. 1):

[...] nenhuma pessoa jurídica atua diretamente no mundo. Toda pessoa jurídica se vale de pessoas físicas. As práticas de corrupção são consumadas por meio de condutas de uma ou mais pessoas físicas. Somente se consuma uma das infrações previstas na Lei 12.846/13 quando a conduta da pessoa física for eivada de um elemento subjetivo reprovável. Esse elemento será necessariamente o dolo. Em momento algum a Lei $\mathrm{n}^{\circ}$. 12.846/2013 instituiu uma espécie de 'corrupção objetiva', em que seria bastante e suficiente a ocorrência de eventos materiais. Ocorre que, consumada a infração em virtude da conduta reprovável de um ou mais indivíduos, poderá produzir-se a responsabilização de pessoa jurídica. Essa responsabilização será 'objetiva', na acepção de que bastará a existência de um vínculo jurídico com a pessoa física infratora. Configurar-se-á a responsabilidade objetiva da pessoa jurídica se o indivíduo que cometeu a infração for a ele relacionado, ainda não na qualidade de administrador ou representante. $O$ vínculo exigido compreende os casos de representação formal, mas também abrange aquelas hipóteses me que a pessoa jurídica forneceu elementos ou recursos para a prática da infração. Mais precisamente, é indispensável existir um vínculo que permitisse à pessoa jurídica controlar a conduta do indivíduo infrator, especificamente para adotar as providências necessárias a impedir a prática da infração.

Porém, o artigo terceiro da lei dispõe que "A responsabilização da pessoa jurídica não exclui a responsabilidade individual de seus dirigentes ou administradores ou de qualquer pessoa 
natural, autora, coautora ou partícipe do ato ilícito". E em seu $\S 2^{\circ}$ afirma que os dirigentes ou administradores somente serão responsabilizados por atos ilícitos na medida da sua culpabilidade, o que demonstra que pessoas físicas também serão responsabilizadas na medida de sua culpabilidade, a par da responsabilização objetiva das pessoas jurídicas (BRASIL, 2013).

Campos (2015, p. 165) se manifesta:

Dessa forma, é possível a seguinte afirmação: enquanto a pessoa jurídica é responsabilizada objetivamente pelos atos ilícitos praticados, os dirigentes e administradores da pessoa jurídica penalizada terão suas condutas analisadas sob o prisma da responsabilidade subjetiva, pois a responsabilização da pessoa jurídica não exclui a responsabilidade individual de quaisquer pessoas naturais.

Desta forma, visa à lei a responsabilidade de todos os que se envolverem em condutas ilícitas para que se tenha um efetivo combate à corrupção no país.

\subsubsection{Acordo de leniência}

O acordo de leniência vem disposto no art.16 que diz:

A autoridade máxima de cada órgão ou entidade pública poderá celebrar acordo de leniência com as pessoas jurídicas responsáveis pela prática dos atos previstos nesta Lei que colaborem efetivamente com as investigações e o processo administrativo, sendo que dessa colaboração resulte; I - a identificação dos demais envolvidos na infração, quando couber; e II - a obtenção célere de informações e documentos que comprovem o ilícito sob apuração. $\S 1^{\circ} \mathrm{O}$ acordo de que trata o caput somente poderá ser celebrado se preenchidos, cumulativamente, os seguintes requisitos: I - a pessoa jurídica seja a primeira a se manifestar sobre seu interesse em cooperar para a apuração do ato ilícito; II - a pessoa jurídica cesse completamente seu envolvimento na infração investigada a partir da data de propositura do acordo; III - a pessoa jurídica admita sua participação no ilícito e coopere plena e permanentemente com as investigações e o processo administrativo, comparecendo, sob suas expensas, sempre que solicitada, a todos os atos processuais, até seu encerramento. $\S 40 \mathrm{O}$ acordo de leniência estipulará as condições necessárias para assegurar a efetividade da colaboração e o resultado útil do processo. $\S 5$ o Os efeitos do acordo de leniência serão estendidos às pessoas jurídicas que integram o mesmo grupo econômico, de fato e de direito, desde que firmem o acordo em conjunto, respeitadas as condições nele estabelecidas.§ 6o A proposta de acordo de leniência somente se tornará pública após a efetivação do respectivo acordo, salvo no interesse das investigações e do processo administrativo.§ 7o Não importará em reconhecimento da prática do ato ilícito investigado a proposta de acordo de leniência rejeitada.§ 8o Em caso de descumprimento do acordo de leniência, a pessoa jurídica ficará impedida de celebrar novo acordo pelo prazo de 3 (três) anos contados do conhecimento pela administração pública do referido descumprimento. $\S 9^{\circ}$ A celebração do acordo de leniência interrompe o prazo prescricional dos atos ilícitos previstos nesta Lei. $\S 10$. A Controladoria-Geral da União - CGU é o órgão competente para celebrar os acordos de leniência no âmbito do Poder Executivo federal, bem como no caso de atos lesivos praticados contra a administração pública estrangeira (BRASIL, 
A Administração Pública celebra com o administrado um acordo, que tem por objeto substituir, em determinada relação administrativa, uma conduta, primariamente exigível, por outra secundariamente negociável. Porém, para que o acordo de leniência possa ser celebrado, a pessoa jurídica deve atender a alguns requisitos previstos na legislação, como os previstos no art.16, $\S 1^{\circ}$ inciso I, II e III. Assim, como visto, a pessoa jurídica deverá ser a primeira a se manifestar sobre seu interesse em cooperar para a apuração do ato ilícito, fará cessar completamente seu envolvimento na infração investigada a partir da data de propositura do acordo, bem como, terá de admitir sua participação no ilícito e cooperar com as investigações e o processo administrativo, comparecendo, sob suas expensas, sempre que solicitada, até seu encerramento.

Importante destacar pontos de maiores relevâncias deste artigo. Críticas surgem a partir do caput do artigo, pois se entende que as autoridades legitimadas para celebração de acordos de leniência são as mais investigadas por atos de corrupção, o que poderia comprometer o instituto e trazer descrédito.

Outra alternativa é a regulamentação complementar da LAC pelos Estados, Municípios e Distrito Federal, de modo que cada um destes entes federativos indique órgão correcional e disciplinar próprio, suficientemente autônomo e independente, responsável pela oficialização de pactos de leniência dentro da respectiva estrutura administrativa (PEREIRA, 2016, p. 91).

Em contrapartida, haverá o abrandamento de penalidades impostas a pessoa jurídica que assinar o acordo, entretanto, a obrigação de reparar o dano será mantida. Diferentemente do que dispõe a Lei Antitruste, a primeira a trazer a figura do acordo de leniência, a Lei Anticorrupção não permite que o acordo seja feito junto a pessoas físicas, pois se assim ocorrer, desvirtuaria todo seu sentido e alcance.

Além do trazido anteriormente, questão interessante é sobre a importância da pessoa física ser beneficiária do acordo, pois ela será a responsável pela comunicação dos atos ilícitos que a empresa vem realizando e depois poderá ser processada com as mesmas provas que trouxe para que o acordo de leniência fosse realizado para a pessoa jurídica, sem direito ao acordo que será proposta para aquela.

Neste sentido, manifesta-se Pereira (2016, p. 92 apud RIZZO NETO, 2014, p. 1),

[...] nessa situação, qual o incentivo que os executivos das empresas terão em requerer os benefícios da leniência por atos violadores da Lei Anticor-rupção, com benefícios exclusivos à empresa para a qual eles trabalham, sabedores de que na sequência, com as provas fornecidas, eles próprios serão processados criminalmente? A Lei Anticorrupção brasileira acaba de começar a produzir efeitos, mas ao que parece o acordo de leniência nela previsto é natimorto. 
Após celebrado o acordo de leniência, caberá a entrega de toda documentação e provas necessárias, como traz o inciso III, do $\S 1^{\circ}$ do art. $16 \mathrm{e}$, ainda, "cooperar plena e permanentemente com as investigações e o processo administrativo, comparecendo, sob suas expensas, sempre que solicitada, a todos os atos processuais, até seu encerramento". Poderá ser entendido como ato de descumprimento do acordo a recusa em prestar confissões, entregar documentos e outros meios de provas. Tal fato impossibilitaria de a empresa celebrar novo acordo, conforme estabelecido no $\S 8^{\circ}$ do artigo 16 , bem como a pessoa jurídica teria sua anotação efetivada no Cadastro Nacional de Empresas Punidas (BRASIL, 2013).

Embora o acordo traga benefícios à pessoa jurídica, por certo, ela não está obrigada a aceitálo, não sendo sua recusa ou desistência entendida como reconhecimento de ato ilícito. Pode ocorrer de o acordo não ser satisfatório a ela, ou mesmo aos órgãos de investigação. Assim ocorrendo, toda a documentação é devolvida e não poderá ser utilizada para fins de responsabilização.

Caso ocorra a aceitação, deverá trazer informações relevantes e que colaborem significativamente com a persecução criminal, sob pena de ser rejeitada sua proposta pela autoridade encarregada do acordo.

\subsubsection{O Cadastro das pessoas jurídicas}

Estabelecido nas disposições finais, o Cadastro Nacional das Pessoas Jurídicas tem a finalidade de tornar públicas as sanções que foram impostas pelo Poder Público as punições que empresas vieram a sofrer em decorrência da prática de atos que atingiram a Administração Pública, juntamente com acordos de leniência, sendo atualizado de forma periódica.

O Cadastro Nacional de Pessoas Jurídicas no âmbito do Poder Executivo Federal é responsável por reunir e dar publicidade às sanções aplicadas pelos órgãos ou entidades dos Poderes Executivo, Legislativo e Judiciário de todas as esferas de governo, os quais deverão informar e manter atualizados no Cadastro Nacional de Empresas Inidôneas e Suspensas - CEIS, os dados relativos às sanções por eles aplicadas, nos termos do disposto nos artigos 87 e 88 da Lei $n^{\circ} 8.666$, de 21 de junho de 1993 (CAMPOS, 2015).

Através do cadastro haverá a divulgação do nome da empresa envolvida em algum ato ilícito, o que trará consequências negativas a sua reputação e poderá desestimular a prática de tais atos, no intuito de sempre manter a empresa com uma imagem ética para relações empresariais.

$\mathrm{O} \S 2^{\circ}$ do art.22 traz que deverá conter como informações do cadastro a razão social e número de inscrição da pessoa jurídica ou entidade no Cadastro Nacional da Pessoa Jurídica - CNPJ, tipo de sanção e data de aplicação e data final da vigência do efeito limitador ou impeditivo da sanção, quando for o caso, devendo ser incluída no CNEP referência ao respectivo descumprimento.

Ainda, em seu $\S 5^{\circ}$, dispõe sobre a exclusão do nome da pessoa jurídica após o cumprimento das sanções e acordos de leniência, assim como da reparação de eventual dano causado, através de solicitação ao órgão responsável, prescrevendo em cinco anos as infrações previstas nesta lei, a 
partir do momento da ciência de cada infração, não afetando demais infrações previstas nas demais leis correlatas.

\section{DAS FORMAS DE RESPONSABILIDADES PELOS ATOS PRATICADOS NA LEI 12.846/13}

Para a configuração da responsabilidade civil da pessoa jurídica, necessário se faz a prática de determinados atos estabelecidos no art. $5^{\circ}$, atentando contra o patrimônio público nacional ou estrangeiro, princípios da Administração Pública ou compromisso internacionais assumidos pelo Brasil, conforme dispostos da seguinte maneira:

I - prometer, oferecer ou dar, direta ou indiretamente, vantagem indevida a agente público, ou a terceira pessoa a ele relacionada; II - comprovadamente, financiar, custear, patrocinar ou de qualquer modo subvencionar a prática dos atos ilícitos previstos nesta Lei; III - comprovadamente, utilizar-se de interposta pessoa física ou jurídica para ocultar ou dissimular seus reais interesses ou a identidade dos beneficiários dos atos praticados; IV - no tocante a licitações e contratos: a) frustrar ou fraudar, mediante ajuste, combinação ou qualquer outro expediente, o caráter competitivo de procedimento licitatório público; b) impedir, perturbar ou fraudar a realização de qualquer ato de procedimento licitatório público; c) afastar ou procurar afastar licitante, por meio de fraude ou oferecimento de vantagem de qualquer tipo; d) fraudar licitação pública ou contrato dela decorrente; e) criar, de modo fraudulento ou irregular, pessoa jurídica para participar de licitação pública ou celebrar contrato administrativo; f) obter vantagem ou benefício indevido, de modo fraudulento, de modificações ou prorrogações de contratos celebrados com a administração pública, sem autorização em lei, no ato convocatório da licitação pública ou nos respectivos instrumentos contratuais; ou g) manipular ou fraudar o equilíbrio econômico-financeiro dos contratos celebrados com a administração pública; V - dificultar atividade de investigação ou fiscalização de órgãos, entidades ou agentes públicos, ou intervir em sua atuação, inclusive no âmbito das agências reguladoras e dos órgãos de fiscalização do sistema financeiro nacional (BRASIL, 2013).

As sanções que poderão serem aplicadas vêm dispostas no art.19, podendo ser usadas de forma isolada ou cumulativamente, após devido processo legal. Entre as sanções, estão o perdimento de bens, direitos e valores, suspensão ou interdição parcial de suas atividades e a dissolução compulsórias de suas atividades. Contudo, esta última só poderá ser aplicada quando comprovado ter sido a personalidade jurídica utilizada de forma habitual para facilitar ou promover a prática de atos ilícitos, e ainda, ter sido constituída para ocultar ou dissimular interesses ilícitos ou a identidade dos beneficiários dos atos praticados, conforme estabelecido no $\S 1^{\circ}$, incisos I e II do art.19.

Dispostas no art. $6^{\circ}$, a responsabilização administrativa pelos atos lesivos, sendo eles:

Art. $6^{\circ} \mathrm{Na}$ esfera administrativa, serão aplicadas às pessoas jurídicas consideradas 
responsáveis pelos atos lesivos previstos nesta Lei as seguintes sanções: I - multa, no valor de $0,1 \%$ (um décimo por cento) a $20 \%$ (vinte por cento) do faturamento bruto do último exercício anterior ao da instauração do processo administrativo, excluídos os tributos, a qual nunca será inferior à vantagem auferida, quando for possível sua estimação; e

II - publicação extraordinária da decisão condenatória.

$\S 1$ o As sanções serão aplicadas fundamentadamente, isolada ou cumulativamente, de acordo com as peculiaridades do caso concreto e com a gravidade e natureza das infrações.

§ 2o A aplicação das sanções previstas neste artigo será precedida da manifestação jurídica elaborada pela Advocacia Pública ou pelo órgão de assistência jurídica, ou equivalente, do ente público.

§ 3o A aplicação das sanções previstas neste artigo não exclui, em qualquer hipótese, a obrigação da reparação integral do dano causado.

$\S 4$ o Na hipótese do inciso I do caput, caso não seja possível utilizar o critério do valor do faturamento bruto da pessoa jurídica, a multa será de $\mathrm{R} \$ 6.000,00$ (seis mil reais) a $\mathrm{R} \$ 60.000 .000,00$ (sessenta milhões de reais).

$\S 50$ A publicação extraordinária da decisão condenatória ocorrerá na forma de extrato de sentença, a expensas da pessoa jurídica, em meios de comunicação de grande circulação na área da prática da infração e de atuação da pessoa jurídica ou, na sua falta, em publicação de circulação nacional, bem como por meio de afixação de edital, pelo prazo mínimo de 30 (trinta) dias, no próprio estabelecimento ou no local de exercício da atividade, de modo visível ao público, e no sítio eletrônico na rede mundial de computadores (BRASIL, 2013).

Para que tais sanções sejam aplicadas, também é necessária a ocorrência de um ilícito administrativo, que também já haviam sido previstas na Lei de Improbidade Administrativa e Lei das Licitações Públicas, não constituindo inovação no ordenamento jurídico brasileiro.

A penalidade de multa é aplicada através de valores elevados com a finalidade de inibir qualquer ação da pessoa jurídica na prática de corrupção. Entretanto, surgem críticas quanto aos valores elevados de tais sanções, trazendo como desproporcionais e muitas vezes impossíveis de serem pagas, o que descaracterizaria sua finalidade. Ou ainda, a desproporcionalidade da multa permite que a empresa não possa continuar com suas atividades, exercendo a multa finalidade nitidamente arrecadatória.

A outra penalidade imposta em âmbito administrativo refere-se à publicação extraordinária da decisão condenatória. No $\S 5^{\circ}$ traz que ocorrerá na forma de extrato de sentença, às expensas da pessoa jurídica, em meios de comunicação de grande circulação na área da prática da infração e de atuação da pessoa jurídica ou, na sua falta, em publicação de circulação nacional, bem como por meio de afixação de edital, pelo prazo mínimo de 30 (trinta) dias, no próprio estabelecimento ou no local de exercício da atividade, de modo visível ao público, e no sítio eletrônico na rede mundial de computadores.

Evidentemente, as sanções serão avaliadas de acordo com o grau de gravidade e envolvimento, grau de lesão, entre outros, ressaltando, ainda, que tais penalidades não colidirão com eventuais penalidades que possam a serem aplicadas em demais leis, como de Improbidade 
Administração e Licitações Públicas.

\section{CONCLUSÃO}

Nos últimos anos o Brasil vem sofrendo um dos maiores escândalos de corrupção de sua história, recebendo inúmeros protestos com milhares de pessoas nas ruas reivindicando um país mais ético, transparente, com menos casos de corrupção e punição para quem cometeu atos ilícitos;

Assim, foi promulgada a Lei 12.846/13, com o intuito de responsabilização administrativa e civil de pessoas jurídicas pela prática de atos contra a administração pública, nacional ou estrangeira, em hipóteses de cometimento, por seus funcionários, de atos definidos como lesivos à Administração Pública, sendo popularmente conhecida por lei anticorrupção;

Através desta lei, surgem a responsabilidade objetiva da pessoa jurídica e graves consequências em decorrência de ilícitos praticados, surgindo críticas junto a essa responsabilidade, pois a pessoa física é quem comete tais atos utilizando-se da pessoa jurídica;

Traz como mecanismos de consideração de aplicação da pena a existência de mecanismos e procedimentos internos de integridade, auditoria e incentivo à denúncia de irregularidades e a aplicação efetiva de códigos de ética e de conduta no âmbito da pessoa jurídica, ou seja, o programa compliance;

Ainda, trazer a relação do programa compliance com demais ramos do Direito e os efeitos que poderá ocorrer na sociedade em decorrência de sua utilização de forma correta e ética, passando por uma grande conscientização social sobre as consequência e danos que a corrupção gera a sociedade;

Na Administração Pública o compliance faz com que o gestor público acabe executando atividades cada vez mais burocráticas, o que afasta a presunção de legalidades dos atos administrativos e já há princípios constitucionais que norteiam o setor público, em especial o Princípio da Supremacia do Interesse Público, independendo de padrões;

Por fim, conclui-se que o ordenamento jurídico brasileiro dispõe de inúmeras leis que tratam de atos de corrupção e, mesmo assim existindo, não foram suficientes para evitar que fossem praticados, como a Lei de Improbidade Administrativa(8.429/92), Lei da Ação Popular(4.717/65), Lei da Ação Civil Pública(7.347/85), Lei de responsabilidade fiscal(Lc 101/00), Lei da Ficha Limpa(Lc105/00), Crimes de Responsabilidade(1.079/50), Lei de lavagem de dinheiro(9.613/98), Código Penal, além de outras que sem um aparato adequado dos órgãos de investigação e estrutura do Poder Judiciário não foram capazes de impossibilitar diversos casos que atentaram contra a Administração Pública, sendo a Lei 12.846/13 um excesso legislativo que poderia ser facilmente suprido pelas legislações já existentes.

\section{REFERÊNCIAS}

ASSIS, Sérgio Augusto Alves de. Norma anticorrupção e os programas de compliance no Direito Brasileiro. 2016. 96 f. Dissertação (Mestrado em Direito) - Universidade de Marília. 
2016. Disponível em: http://www.unimar.br/pos/trabalhos/arquivos/5965102655B0D22CE4A8F3 24DCCA66AA.pdf. Acesso em: 1 fev. 2018.

BRASIL. [Constituição (1988)]. Constituição da República Federativa do Brasil de 1988. Disponível em: http://www.planalto.gov.br/ccivil_03/constituicao/constituicao.htm. Acesso em: 4 jan. 2018.

BRASIL. Lei 9.613/98, de 03 de março de 1998. Disponível em: http://www.planalto.gov.br/ ccivil_03/_ato2011-2014/2012/lei/112651.htm. Acesso em: 25 jan. 2018.

BRASIL. Lei 12.846, de 01 de agosto de 2013. Disponível em: http://www.planalto.gov.br/ ccivil_03/leis/L6001.htm. Acesso em: 28 jan. 2018.

CAMPOS, Patrícia Toledo de. Comentário à lei no 12.846/13: lei anticorrupção. Revista Digital de Direito Administrativo, São Paulo, v. 2, n. 1, p. 160-185, 2015. Disponível em: https://www. revistas.usp.br/rdda/article/download/80943/92155. Acesso em: 1 fev. 2018.

GABARDO, Emerson; CASTELLA, Gabriel Morettini. A nova lei anticorrupção e a importância do compliance para as empresas que se relacionam com a Administração Pública.

Revista de Direito Administrativo \& Constitucional, Belo Horizonte, v. 15, n. 60, p. 129-147, 2015. Disponível em: http://www.editoraforum.com.br/wp-content/uploads/2015/08/leianticorru pcao-compliance.pdf. Acesso em: 1 fev. 2018.

JUSTEN FILHO, Marçal. A “nova” lei anticorrupção brasileira (Lei federal 12.846/13). Disponível em: http://www.justen.com.br//informativo.php?\&informativo=82\&artigo=111 $0 \& 1=$ pt. Acesso em: 1 fev. 2018.

OLIVEIRA, André Araújo. A incidência da lei anticorrupção e do compliance no âmbito trabalhista. Revista do Curso de Direito da Faculdade de Humanidades e Direito, São Paulo, v. 12, n. 12, p. 167-187, 2015. Disponível em https://www.metodista.br/revistas/revistasims/ index .php/RFD/article/download/6614/5183. Acesso em: 1 fev. 2018.

PEREIRA, Victor Alexandre El Khoury M. Acordo de leniência na lei anticorrupção (lei n ${ }^{\circ}$ 12.846/2013). Revista Brasileira de Infraestrutura, Belo Horizonte, v. 5, n. 9, p. 79-113, 2016. Disponível em: http://www.editoraforum.com.br/wp-content/uploads/2017/03/acordo-leniencialei-anticorrup cao.pdf. Acesso em: 29 jan. 2018.

RIBEIRO, Márcia Carla Pereira; DINIZ, Patrícia Dittrich Ferreira. Compliance e lei anticorrupção nas empresas. Revista de Informação Legislativa, Brasília, v. 52, n. 205, p. 87105, 2015. Disponível em: https://www12.senado.leg.br/ril/edicoes/52/205/ril_v52_n205_p87. pdf. Acesso em: 1 fev. 2018.

RIZZO NETO, Eloy. Acordo de leniência da lei anticorrupção apresenta falhas. Disponível em: http://www.conjur.com.br/2014-mar-14/eloy-rizzo-neto-acordo-leniencia-leianticorrupcao -apresentafalhas\#author. Acesso em: 1 fev. 2018.

SAAVEDRA, Giovani Agostini. Compliance criminal: revisão teórica e esboço de uma delimitação conceitual. Revista Duc In Altum Cadernos de Direito, Porto Alegre, v. 8, n. 15, p. 239-255, 2016. Disponível em: http://www.faculdadedamas.edu.br/revistafd/index.php/cihjur/arti 
cle/view/375. Acesso em: 1 fev. 2018.

Como citar: SILVEIRA, Daniel Barile; JORGE, Carlos Henrique Miranda. O compliance e seus reflexos no direito brasileiro. Scientia Iuris, Londrina, v. 23, n. 1, p. 125-143, mar. 2019. DOI: 10.5433/2178-8189.2019v23n1p125. ISSN: 2178-8189.

Recebido em: 17/09/2018.

Aprovado em: 23/02/2019. 